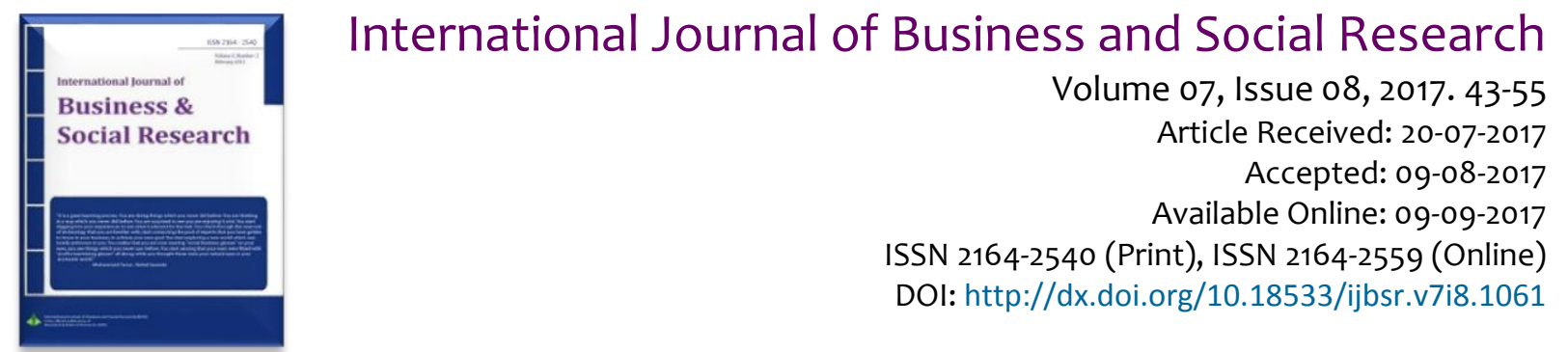

\title{
Essential Skills for Project Stakeholders Identification: Sustainability Perspective
}

\author{
Md. Mashiur Rahman', Madad Ali², Naveed Malik³, Muhammad Salman Ahmad4, \\ Fahad Asmi ${ }^{5}$
}

\begin{abstract}
In every life cycle of the project there are numerous people or organizations involved either directly or indirectly. While these type of people and organizations involved are called stakeholders and these may include the project team, client or customer, community, environment, suppliers, government. Stakeholders contribute and share their experiences, knowledge, and insights to support the project throughout its life cycle and therefore it is crucial to capture their input. However, before initiation of the project, stakeholders need to be identified. Following the fact that there are strategies and processes for stakeholder identification, it is not clear what skills are needed to employ those strategies for stakeholder identification. These skills are exceedingly important to have because in today's corporate world, the project team must be flexible in every aspect of their job and be able to complement their skills for the success of stakeholder identification. Using literature review, this paper seeks to describe the skills of project leader needed to identify the project team and the external stakeholders. Inductive approach was followed in this study and data was collected qualitatively using secondary sources. There are two essential skills i.e. relationship building skills and communication skills for internal stakeholders and four major skills i.e. communication skills, people skills, intellectual skills and conceptual skills for external stakeholders are identified for the identification of project stakeholders through literature review considering the sustainability issues in the project management.
\end{abstract}

Keywords: Corporate Social Responsibility (CSR), Project Skills, Stakeholder Identification, Sustainable Project. JEL Codes: J24, M100, Q5.

This is an open access article under Creative Commons Attribution 4.0 License, 2017.

\footnotetext{
1 Ph.D. Research Scholar, School of Public Affairs, University of Science and Technology of China, Hefei, Anhui, P.R. China, E-mail: mashiur@mail.ustc.edu.cn

2 Ph.D. Research Scholar, School of Public Affairs, University of Science and Technology of China, Hefei, Anhui, P.R. China, E-mail: ali12@mail.ustc.edu.cn

3 Post-graduate Student, School of Public Affairs, University of Science and Technology of China, Hefei, Anhui, P.R. China, E-mail: nam@mail.ustc.edu.cn

4 Ph.D. Research Scholar, School of Public Affairs, University of Science and Technology of China, Hefei, Anhui, P.R. China, E-mail: sahmad@mail.ustc.edu.cn

5 Ph.D. Research Scholar, School of Public Affairs, University of Science and Technology of China, Hefei, Anhui, P.R. China, E-mail: fasmie@mail.ustc.edu.cn
} 


\section{Introduction}

\subsection{Stakeholder identification in projects}

According to PMI (2008), project management is the application of skills, knowledge, and techniques to carry out projects in an effective and efficient way. The success of a project does not only involve the delivery of a product, service or result on time, but also within budget and scope (Bourne and Walker, 2005). They expressed that it also involves paying attention to the needs and expectations of diverse range of project stakeholders and get them satisfied by the process of the project and the deliverable as they are the ones who ultimately determine whether a project is a success or not. Eskerod and Huemann (2013:40), Donaldson and Preston (1995) define stakeholders as "individuals or groups with legitimate interests in procedural and/or substantive aspects of corporate activity and are identified by their interests in the organization, whether the organization has any interest in them". Werther and Chandler (2011:34) said, "...these can include individuals and groups both inside and outside of the organization".

Alladi and Vadari (2011) identify key stakeholders in a project as project team, client's customers, organizational management, organizational employees, Government, regulatory body and technology teams. They go on to say in a business environment that the stakeholders could be creditors, customers, directors, employees, government and its agencies, owners, suppliers, unions, press and media and the community from which business operates. However Cobb (2012) argues that although thoroughly identified, stakeholders have conflicting interests and desires that might be difficult balance. Nevertheless, Cleland (1999) offers processes for managing stakeholders and these include identifying the rightful stakeholders, specifying and analyzing the nature of their interests and may be to predict their responses in the long run. To avoid more conflicts, Eskerod and Huemann (2013) suggest identifying and interacting with limited number of stakeholder. Figure 1 illustrates help team members to visualize and understand where stakeholders may emerge from Walker (2003) cited in Bourne and Walker 2005. The project leader and team member are in the central position indicating that they are responsible for identifying the stakeholders and keep them on track.

Figure 1: Stakeholder model (Walker, 2003)

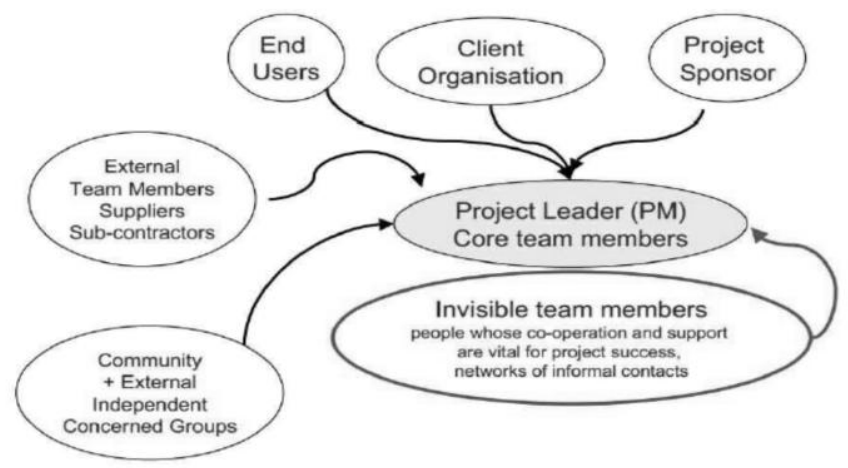

Ballejoes and Montagna (2008) argues that project leaders face challenges to deliver successful projects as stakeholders are the first emerging challenge in any project as their identification is critical task for success. Bourne and walker (2005) postulates that traditionally, development of tools, techniques and frameworks to identify stakeholders and managing relationships with them has been the subject of a muted focus. However Eskerod and Huemann (2013) define two variations of stakeholder relations within project management: management of stakeholders and management for stakeholders. Management of stakeholders treats the stakeholder as means to an end, and does not take the needs of the stakeholder as seriously as the needs of the project (Eskerod \& Huemann, 2013). Management for stakeholders treats all stakeholders as having value and importance in the decisions of the organization [in this context the project] and that good solutions involve a "win-win" situation between both parties (Eskerod \& Huemann, 2013). Therefore, this study takes the second approach to identification stakeholders. 
Since stakeholders are considerable assets in contributing knowledge, and support in fulfilling the outcomes of the projects, tools and skills that help project to identify stakeholders are critical. Walker, Bourne and Shelley (2008) opined that stakeholder identification is recognized as key project management skills and refer them to 'soft' skills. However, in this study they will just be referred to skills rather than soft skills. Schieg (2009:321) says 'high social competency' is required in stakeholder identification as there are challenges in trying to include people from diverse backgrounds. This study assumes that failure to identify proper stakeholders leads to failure of the project. This is line with Morris and Hough (1993) cited in Bourne and walker (2005) that if stakeholder identification is not appreciated led to countless project failures. The research will also assume Eskerod and Jepsen's (2008) argument that stakeholder identification is an ongoing process as coalition of stakeholders often changes because different stakeholders may be important at different stages in the process.

\subsection{The role of corporate social responsibility in projects}

In the backdrop of project management, it is vital to introduce Corporate Social Responsibility (CSR) aspects to projects. This implies that businesses, industries and projects have core responsibilities towards societies in which they operate and the stakeholders are the fundamental fabric of today's projects centric society requiring ample attention from the project goals (Werther and Chandler; 2011). Everyone who the organization impact directly or indirectly is their stakeholder. Again Werther and Chandler (2011) presented a framework that organizations can use to identify stakeholders and divides them into three separate groups that are organizational stakeholders (internal to the organization) and economic and societal stakeholders (external to the organization). Whilst profit may be the end goal for any organization, responsible organizations have managed to attract more investors, and addressed stakeholder concerns. The reality is that no organization operates in isolation; there is interaction with employees, customers, suppliers and stakeholders. Schieg (2009) talk about the roles of CSR in projects and these are growing social competence, employee motivation, trust building, cost saving, risk mitigation and image awareness. However they may be hard to measure in cash but the organization gets integrity, credibility or reputation. When projects attempt to address the triple bottom line of strategic corporate social responsibility (Economic, Social and Environmental)(Werther \& Chandler, 2011), it "requires specific underpinning values of the attitude and behavior of the project manager and project team members when doing stakeholder identification" (Eskerod \& Huemann, 2013).

\subsection{Organizing and leading sustainable projects teams}

Tolbert and Hall (2009) talks about organizational structure and postulate that structures influence and shape people's practices. They further talk about bureaucratic structure with fixed division of labor- task and responsibility with hierarchy of authority and written rules to enable decision-making. However, in project teams where different people have to complement their skills, this kind of structure therefore lacks employee freedom to be creative and lowers their morale exercise their skills and work to their full potential (Tolbert and Hall 2009). The team therefore requires a horizontal structure also referred to as flat management structure, with virtually no bureaucracy (Tolbert and Hall 2009). Moreover, formal reporting structures should be less important than informal consultations and discussions.

Leadership, in project stakeholder identification and management requires a number of techniques and the ability to adapt to any type of situation. In order to ensure that a project including stakeholder identification is carried out properly, the project team must effectively apply project management processes (PMI, 2013). A leader's role becomes creating an environment where the project team can achieve their full potential as they help move the project toward its goals. Instead of viewing themselves as resource controllers leaders must view themselves as flexible resources willing to engage the team to participate freely. This strategy for empowerment encompasses the path goal theory cited by Northouse (2013), where a leader motivates the followers and empower the project team to reach their full potential while exercising their skills and this requires clarity of the project mission, vision and value, clearly specify the tasks, roles, and rewards for employees, delegate responsibility, and hold people accountable for results. Yueh-shian (2011) argues that it involves trusting people to do the right thing and having a tolerance for failure. They would act with a sense of ownership and typically as forgiveness rather than permission. 


\section{4 \\ Skills in project stakeholder identification}

Generally we found that the project team follows the existing managerial skills in their traditional projects that is constituted of conceptual, technical and human skills (Northouse, 2013). But now a day the project has to compromise with multi-diversified phenomena, CSR activities, environmental vulnerability, global economic crisis etc. (Werther \& Chandler, 2011). For that regards, the project leader should consider sustainability issues in their project stakeholders' identification as well as to acquire couple of essentials skills with existing managerial skills. We tried to go through over the collected literature, unfortunately existing managerial skills (conceptual, technical \& human) didn't fulfill the successful requirements of the project stakeholder identification considering sustainability issues. That's why, we tried to review the literature for searching some additional essential skills that can help the project leader to identify the project stakeholders.

In the background of this study we indicated that stakeholders are very important in all projects and they need to be identified before the initiation and throughout the project. Even though the project leaders/team are organized and lead the team well at the same time using the CSR approaches, stakeholder model and identification strategies to identify the stakeholders, most projects fail to meet their goals because of failure to identify stakeholders; we argue that without proper diverse skills to identify both the project team who will assist in external stakeholder identification, the identification cannot be a success. Using Freeman's work (1984) about stakeholder theory, stakeholder identification has been under research for about three decades and more, it has only given the techniques and strategies on how to identify stakeholders, but research on what skills needed to apply those strategies is still minimum. This is in line with Prabhakar (2008) who raises concerns about a lot of overwhelming advices and strategies given to identify stakeholders, s/he goes on to argue that project leader/team may not have the skills to carry out the work.

Figure 2: Problem formulation model (Own illustration, 2017)
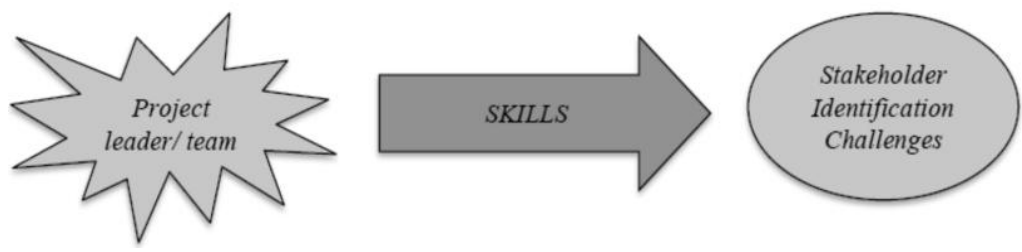

Eskerod and Jepsen's (2008) research revealed that project managers fail to deliver successful projects, as they might not have the skills to carry out that tasks involved in making the necessary inquiries in identification of stakeholders. In this regard Luecke (2004) cited in Yueh-shian bringing together the right people with the right skills to form a team is extremely important. The problem is micro and it will be discussed from an individual perspective as we are concentrating on leader and team dynamics even though in an organizational set up. Therefore, as illustrated in figure 2, we infer that in line with stakeholder strategies and techniques, certain skills are needed to identify both the internal and external stakeholders. Therefore, with the discussions from different perspectives we believe that this constitute a clear-cut significant gap in this area. Considering this gap and looking at the phenomena from a fundamental perspective, the following purpose has been formulated.

\subsection{Purpose of the study}

To fill this gap, the purpose of this study is to describe the skills needed for effective project stakeholder identification. The research assumes that a project leader does not have enough skills to identify external stakeholders therefore has to identify and select the team with diverse and complementary skills in order to identify external stakeholders.

\section{Methodology and methods}

\subsection{Methodology}

This study is based in already existing literature and the reality is from the articles. However, we also searched for other articles from Malmo University (MAH) library database of Sweden through 
summon to try and understand the skills needed to identify internal and external stakeholders. Therefore, assumptions we made are not only based on the articles from the core database but what we constructed from these articles and the ones we searched on my own and therefore to us the nature of social reality is close to the social constructivist ( 6 \& Bellamy, 2012), which imply that there are several absolute truths not just one, and this is line with Blaikie (2003:17) who says "social reality is the symbolic world of meanings and interpretations". From epistemological perspective, we adopted the social constructivism perspective because we analyzed the articles based on the common themes we constructed from strategies, techniques and tools about stakeholder identification and linked them to one research about soft skills. We also took into consideration that there is no one sound strategy for stakeholder identification in project management as it depends on various factors in different situation that vary from project to project (6 \& Bellamy, 2012).

Within the field of social science, it is not possible to observe everything directly and this is why researchers must work with indicators and make inferences ( 6 \& Bellamy, 2012). Therefore, the inference of this study is to describe. Our research purpose is based on existing stakeholder analysis. Therefore, we made the descriptive inference basing on what different researchers are saying about stakeholder identification strategies, techniques and processes. Having discussed the problem using theories and existing knowledge about stakeholder management for pre understanding, the research followed an inductive reasoning. This was done in line with 6 and Bellamy (2012) that an inductive approach starts with a question that lead straight to data collection. Considering that there is no clear research on the skills needed to identify both internal and external stakeholders using the identification strategies and techniques, we were not sure where the research will lead us, we then decided to adopt this approach. In line with the descriptive inference and inductive strategy, for this study the main data was collected qualitatively using secondary data from existing studies about stakeholders in project management. We decided to use the qualitative research approach as its purpose is mainly about understanding, it is interpretative and it allows the researchers to explore (6 \& Bellamy, 2012). With limited time to carry out this research, we limited ourselves to gather soft skills only needed for stakeholder identification rather skills including the technical ones for the whole project.

\subsection{Research methods}

According to 6 and Bellamy (2012:10), data creation methods refer to procedures of constructing raw material for further investigation. In this case data was created through reviewing literature, which included textbooks, academic journals, peer-reviewed articles and other websites. The articles were searched through Malmo University Library's website. This search was extended to the ABI/INFORMGlobal, SAGE Journals, JSTOR, Scopus and Google Scholar database as some of the articles could not be found through summons. We first filtered the articles from the database consisting 1,350 articles and books. We used the keyword 'stakeholders'. After filtering using keyword 'stakeholder' the number was reduced to 34 consisting of both articles and books. We then searched for these articles through summon engine at MAH database. We read all the abstracts, introductions and conclusions from all the articles we had selected. However, an interesting thing we noted is that using a systemic keyword search strategy was not helpful, we realized that content is not always relevant to the problem or the title of the article instead we selected the articles that were relevant to my purpose and the number was narrowed down to 8 .

Table 1: List of articles used as dataset

\begin{tabular}{lll}
\hline No. & Article Name & Author (s) \\
\hline 1 & $\begin{array}{l}\text { Project stakeholder management } \\
2\end{array}$ & $\begin{array}{l}\text { Sustainable Development and Project stakeholder } \\
\text { management: What standard say }\end{array}$ \\
3 & $\begin{array}{l}\text { Systemic approach to project management: A stakeholder } \\
\text { perspective for sustainability }\end{array}$ & Alladi, A. \& Vadari, S. (2011) \\
4 & $\begin{array}{l}\text { Visualizing and mapping stakeholder influence } \\
\text { Stakeholder analysis in projects: Challenge in using current } \\
\text { guidelines in the real world. }\end{array}$ & $\begin{array}{l}\text { Bourne, L. \& Walker, D. H. T. (2005) } \\
\text { Jepsen, A. N. \& Eskerod, P. (2008) }\end{array}$ \\
\hline
\end{tabular}




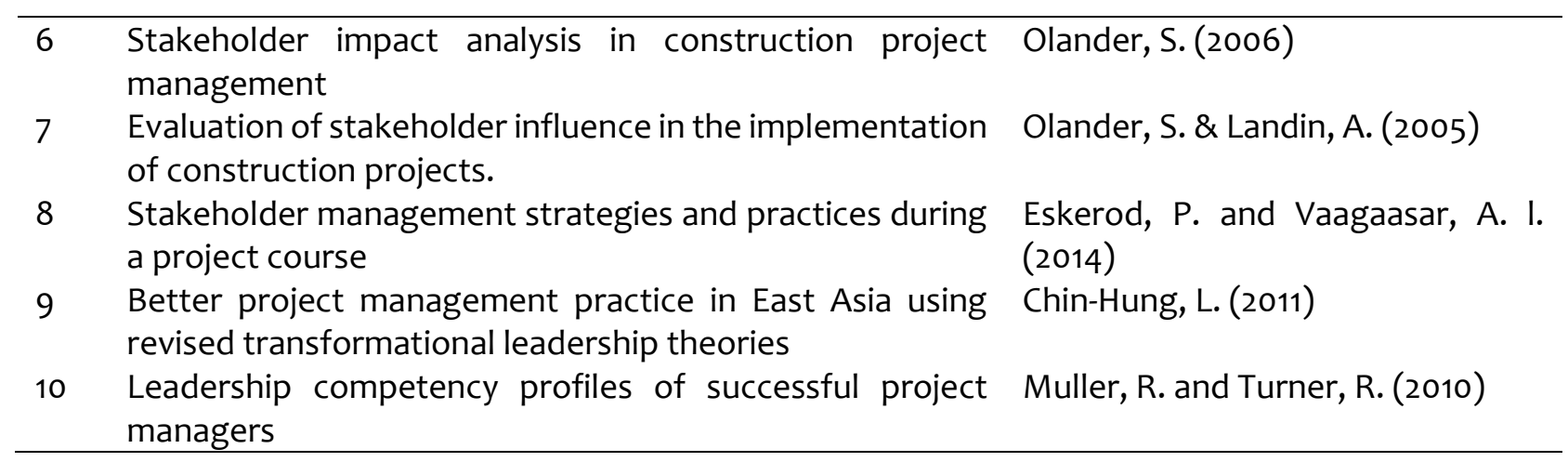

The first search could not completely fill the gap; this lead us to the second literature review with the aim to find out if there are skills need to identify stakeholders. We went back to the database and filtered using key words leadership, project management and skills. In this search we got 10 articles, went to MAH database again but could not obtain the other 6 articles though summon at the end we ended up with 2 articles that provided more different knowledge as it is important to look at the concepts from different perspectives to ensure the variety of input (Silverman, 2011). The main articles used from the database are presented in the table 1 below. However, some other articles and books that are not listed here were obtained from the MAH library database and Google scholar but were used for other basic information mainly to support our discussions and arguments.

Table 2: Categories and concepts

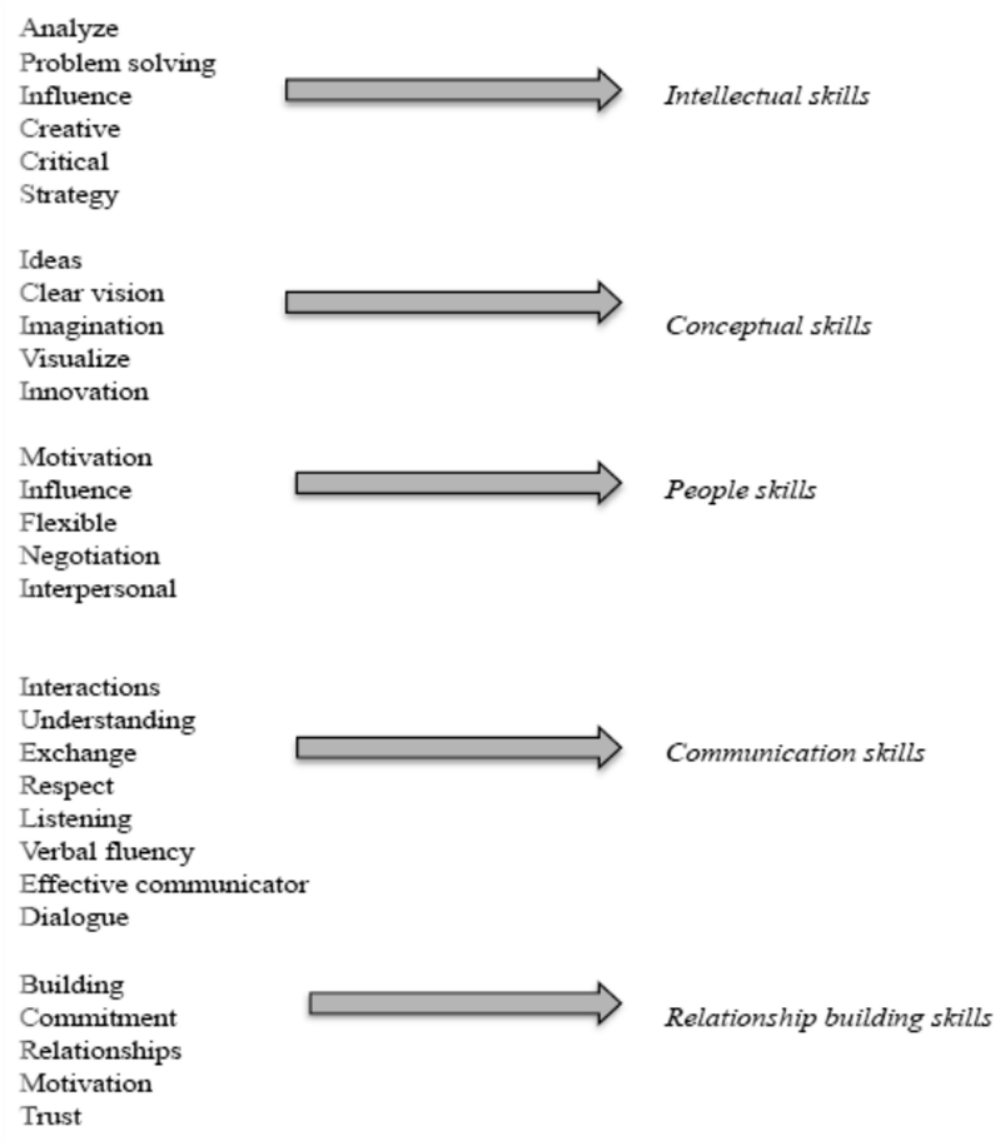

After creating data, we gathered substantial amount of knowledge from the articles. We were more interested in qualitative data. We were not interested much in quantitative data, therefore we left with abstracts, introductions, discussions and conclusions. After we gathered data from core articles, we proceeded to put all the relevant findings in a table in the form of key sentences. We numbered our articles and so this table includes article number, name of the article and all the findings from it that we deemed relevant for answering our purpose. This helped us collect all the significant data in one place. 
Table 2 illustrates the final stage of coding. The codes were created from stakeholder identification strategies, tools and processes linking them to Chin-Hung's (2011) research about soft skills. The soft skills as identified by Chen (2006) cited in Chin-Hung's (2011) are interpersonal skills, communication skills, team building, coordination skills and delegation skills, and problem finding, analyzing, and solving skills". These were there sorted according to the strategies as previously explained above.

After that data was organized through tabulation that allowed coding to be very less time consuming and efficient. We first listed down the strategies for identification of stakeholders described above and then linked them to the soft skills from other research. The last step of data organization was cross checking. Content analysis was used to analyze the data and this was linking the stakeholder identification strategies provided by many searchers from the list provided in table 2 to the Chen's (2006) research cited in Chin-Hung's (2011). Chen's (2006) provided, defined and gave examples about what consists of soft skills. Even though the strategies of identification of stakeholders did not provide what skills are needed, we found a perfect link between these strategies from Chen's (2006) research.

\section{Discussion and analysis}

In this section we presented the discussion and analysis on skills needed to identify the internal stakeholder [the team] and the external stakeholders. The diagram in figure 3 illustrates the main skills need to identify the project team and the main skills for identifying the external stakeholders. However, it doesn't mean the external stakeholders do not need relationship building skills to be identified, they also need relationship building skills from the team.

Figure 3: Stakeholder identification skills model (Own illustration, 2017)

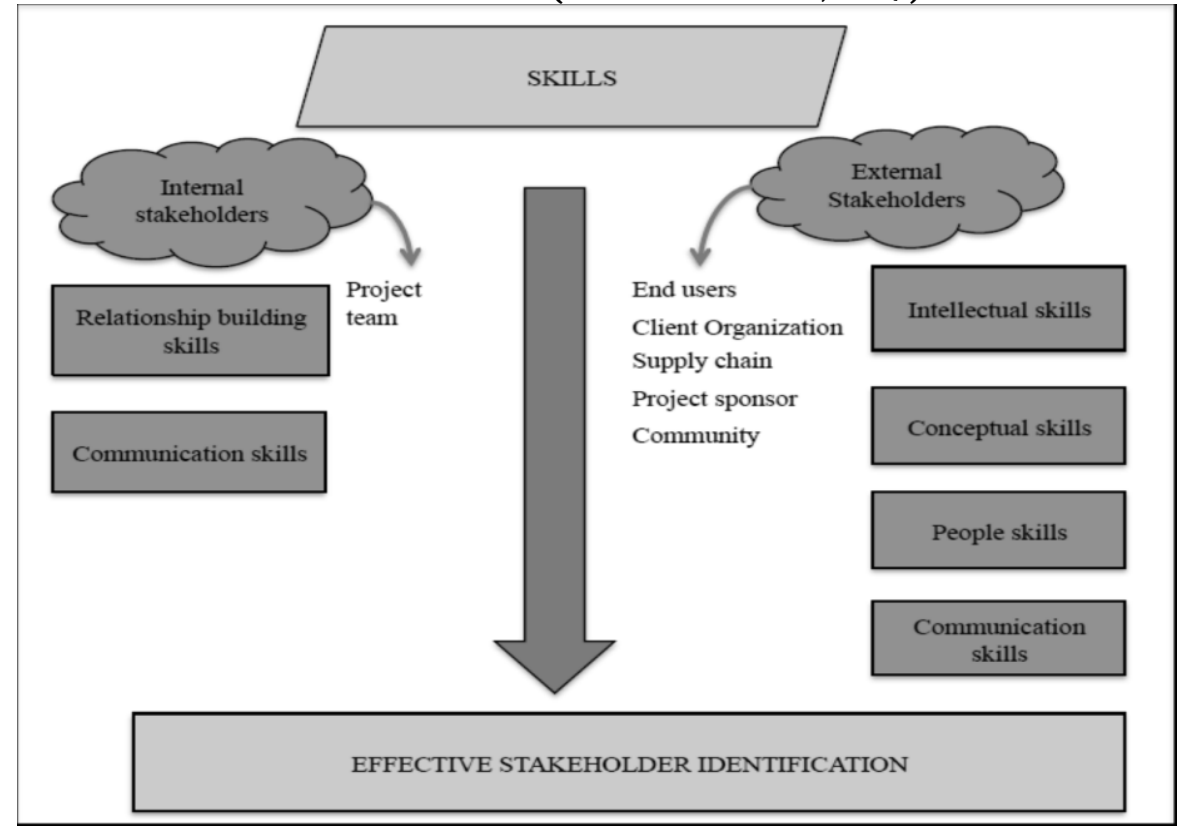

\subsection{Relationship building skills}

Clarkson et al., (2004) notes that the project leader does not want the project to fail because that could impact on his/her job security, rewards, or his/her responsibilities and influence within the organization. Therefore, identifying and selecting high performing team with complementary skills is very important. In this regard Frye, Bennett and Cladwell (2006) however argues that selecting people to work effectively in a team atmosphere can be challenging given the fact that conflict, functional and dysfunctional cases normally arises in working teams, thus identification and hiring the wrong employee can have costly consequences. In this regard, Cleland (1999) cited in Bourne and Walker (2005) postulate that successful completion of project deliverables, however, is critically dependent upon relationship management skills.

Identification of stakeholders brings different people to work together and as noted by Karlsen (2002) the results are depended on the project team's experiences, relationships and capability. In this 
regard, relationship-building skills are essential in identification of internal stakeholders [team]. This means that the teams with good working environment works in harmony and trust each other as well. Karlsen (2002) said that it is necessary to develop an understanding that can generate appreciation and trust that can lead to constructive working relationships. This means that trust is very essential in relationship building in teams and this is in line with Bresnen \& Marshall (2000) who argues that good relationships are built on trust. Eskerod \& Vaagaasar (2014) also argues that relationship is built on trust and give an example about a supplier that was identified, not because of supplier's high technical competency but because of long-term relationship which has been built on trust.

Respect among the team members is also essential that it is critical to build relations by understanding other people's viewpoints therefore avoiding preconceived ideas and assumptions (Olander \& Landin, 2005). Furthermore, Jergeas et al., (2000) noted that the success of a project is through efficient management of the relation between the project and its stakeholders. Therefore, according to House and Shamir (1993) teams with more cohesion and less relationship conflict often perform well because the leader has personalized individual commitment to the team's objectives and the team not only work collaboratively but also to share knowledge. According to Zaccaro, Rittman, and Marks (2001), good work relationships motivate the team and thus motivation becomes a critical team process. Without it, team is not going to exert the necessary effort to complete tasks.

\subsection{Communication skills}

According to Borne and Walker (2005) communication is vital for the project team for relations with stakeholders. It is interesting to note that communication skills impart positively on the relationship building, meaning that communication skills build good relationships between the team and the external stakeholders. The engaging communication competency is an attribute of leader's/ team members that are dynamic and enthusiastic communicators. The leaders will have the ability to communicate procedures, instructions, and their vision to each other and resources (Dulewicz \& Higgs, 2003) cited in Muller and Turner (2010). This method often gives the project teams inspiration and makes the leaders appear approachable and accessible. Chan et al (2006) says that lack of good communication in stakeholder identification may become a major challenge, as it is a primary strategic weapon in countering problems in the identification of stakeholders. Briner et al, (1996) cited in Borne and Walker (2005) says maintenance in the form of "active communication" systems with appropriate stakeholders will also provide "early-warning systems". This basically means that the project team on its own should have open communication and this will help the team members to do the same with the external stakeholders, as it is essential to have good communication flow with them.

Figure 4: Communication strategy (Alladi and Vadari, 2011)

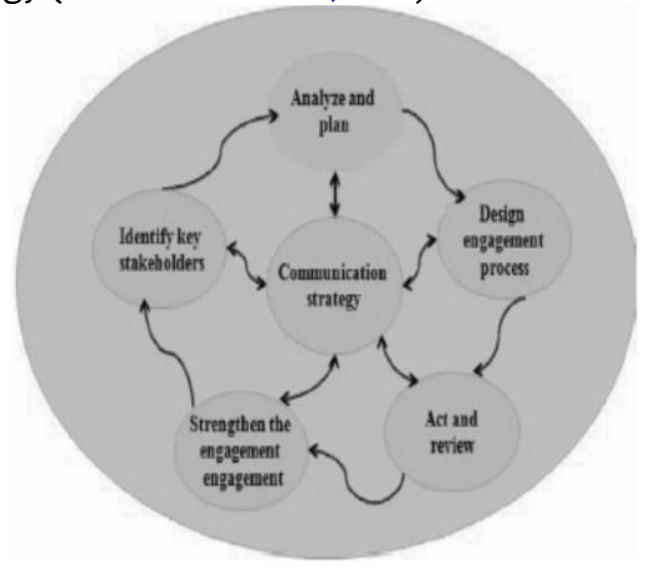

Stakeholders need to be identified early on in the project, in order for the leaders actively to start up a dialogue with them (Alladi \& Vadari, 2011; Cobb, 2010). Alladi and Vadari (2011) in their research as illustrated in figure 4 suggest sustainable communication strategy, they say a project leader/team has to have an evolving strategy while communicating with stakeholders according to their influence and interest. It is important to note that from this diagram above communication strategy is in the central position showing how communication skills are critical to have. Eskerod and Huemann (2013) suggest 
communication through reporting and Alladi and Vadari (2011) support the communication reporting but go on to say that different communication strategies should be employees according to stakeholder influence and interest. This is also important, as there are different stakeholders who need to be attended in different ways as illustrated by the communication strategies below (Alladi \& Vadari 2011; Olander \& Landin 2005):

- High Influence and low interest on the product/service is considered as important stakeholderto satisfy the stakeholder with adequate information.

- High influence and has high interest about the product/service; is considered as key playercommunication strategy should be to manage these stakeholders' effectively

- Low influence and high interest- categorized as affected- communication strategy should be to inform these stakeholders on regular basis to make them aware of the developments.

- Low influence and low interest on the product/service- falls under the category of others, and need to be monitored.

Alladi and Vadari (2011) further state that the medium of communication could be through regular mails, newsletters, periodical meetings and status updates. This therefore requires domain knowledge and communication skills which should both verbal and non-verbal. Eskerod and Vaagaasar (2014) suggest that what make the process of stakeholder management and identification is frequent communication and they give an example about one of their main stakeholder who was a supplier. Their communication structure was done through contractual formalities, formal reporting, reporting meetings, kick-off meetings, as well as management meeting. Savage, Nix, Whithead, and Blair (1991) suggest that the project team should identify and diagnose the stakeholders in order to decide on an over-all strategy for interacting with each of them. Eskerod and Vaagaasar, (2014) is also of the same notion that communication should be prioritized in the projects, as it is central tool in identification of stakeholders. With all the communication and the interactions taking place during the identification of stakeholders, communication skills are required for harmony and good working environment. However this tool presented in figure 4 can be linked to intellectual skills as it also involves analyzing, planning and strategizing processes.

According to Tolbert and Hall (2009), communication is a process that allows people to exchange information by one of several methods and happens at many levels and in many different ways. Good communication skills foster good relations and networks among the project stakeholders. This is in line with Olander and Landin (2005) who postulate that identification of stakeholders requires analysis of their various demands as this helps to facilitate communication between them in early stages of the project. Again Olander and Landin (2005) communication is also essential on avoiding stakeholder conflicts and to reconciling conflicting interests. Poor communication according to Karlsen (2002) may result not only to stakeholder identification failure but also to the project as well.

\subsection{Intellectual skills}

As illustrated in figure 5, Bourne and Walker (2005) suggest a useful tool called stakeholder circle for the project leader that has to understand, remain alert to the nature of stakeholders. This also helps to identify and prioritize project stakeholders. This tool requires critical thinking. This is also in line with Borne and Walker (2005:649) effective project managers require keen analytical and intuitive skills to identify stakeholders and work with them to understand their expectations and influence upon project success. This facilitates managing a process that maximizes stakeholder positive input and minimizes any potential detrimental.

Again Bourne and Walker (2005) said that this tool also helps the project team to find out if their stakeholders know each other and their relationship and this shows the importance of relationships in projects and this is directly linked to relationship building skills discussed above. Using this tool, Jepsen and Eskerod (2008) also postulate that since working with different people with different interests the project team should be able to have the ability to anticipate opportunities and problems for the project at a time and be able to have time for manoeuver. Therefore, intellectual skills are very essential in stakeholder identification and their analysis. 
Figure 5: Stakeholder circle (Bourne and Walker, 2005)

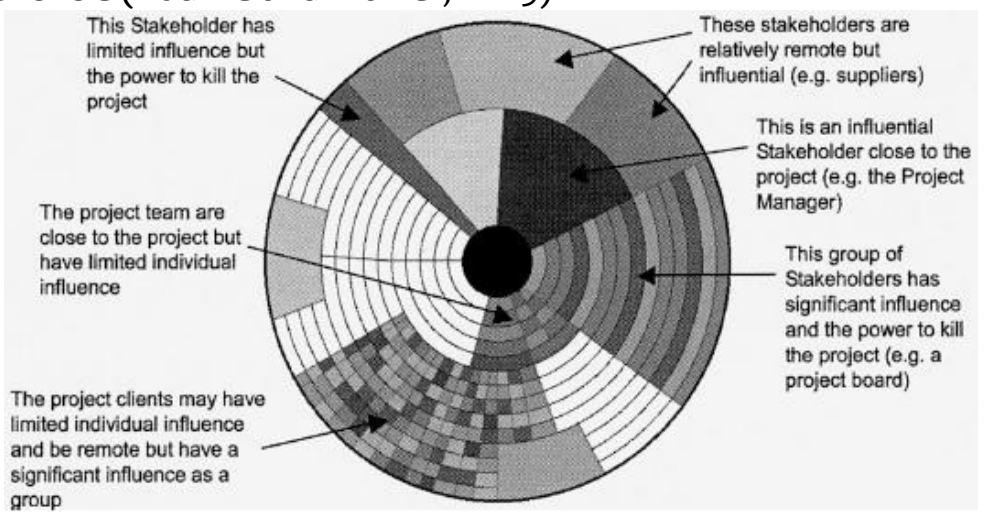

Identification of stakeholder shed a light on who has to deliver the contributions to the project thus Jepsen and Eskerod (2008) also contends that it requires a certain skill as it is a crucial step. Olander and Landin (2005) discussed that the ability to identify and understand the often hidden power and influence of various stakeholders requires a critical skill, as it is important issue for project team, as they have to identify and analyze those stakeholders who can have an influence over decisions. What make it more complex according Olander and Landin (2005) is that the stakeholder's base of influence is not static thus identification should be conducted the entire life cycle of the project. Therefore, as discussed about it essential to have a team with diverse and complementary skills to be to carry out this process thought the project process. Alladi and Vadari (2011) explored identification of stakeholders requires strategically thinking. Therefore, with the critical thinking, analyzing and strategizing we believe that intellectual skills are important carry out this part of stakeholder identification.

\subsection{Conceptual skills}

According to Freeman et al (2008), in order to overcome stakeholder identification challenges one needs to have discipline, clear vision and commitment. Basically a project team needs to articulate the goals and vision of the projects as well as to understand the interests and expectations of stakeholders. However, Walker, Bourne and Shelly (2005) postulates that highly complex problem solving activities, such as stakeholder management particularly identification, can benefit from high level conceptual approaches that allow those involved to see clearly or to visualize the situation being examined. Bourne and Walker (2005) suggested tools for visualizing stakeholders and their influence and this helps to identify appropriate stakeholders; nature of their interests; predicting stakeholder future behavior and evaluating the impact of stakeholder's behavior on the project team latitude in managing the project. The concepts derived from risk management can play a pivotal role in this identification approach. With this approach it can be safe to say the project team should possess conceptual skills.

Galvin, Gibbs, Sullivan and Williams (2014) in their research postulates that visualization and imagination is an important skill in stakeholder identification. They further argue that having a clear vision helps all team members stay focused on project goals. Even in the most complex of projects creativity and imagination with the right people and tools can produce effective and efficient outcomes. Imagination and innovation can bring a fresh perspective for project leaders and their teams by creating new ideas.

\subsection{People skills}

Identification of stakeholders requires the project team able to work and relate well with other people. Prabhakhar (2005) found that people management skills are requires because the project team will be working with many highly skilled and talented proficient [external stakeholder] individuals who expect to be recognized for their expertise by the team. To be able to work well with people will also reduce conflicts in the long run. People skills link directly with relationship building because to be able to work well with the stakeholders will create trust hence build their relationship. Since this skills are mostly involved with people, it is recognized as people skills in this study. Actually this people skills are to some extent close with human skills. Borne and Walker (2005) contends that stakeholder identification requires negotiations, commitment, trust and motivation. The identified stakeholder would want to work 
with the team that they can trust.

Prabhakhar (2008) found that use of a wider range of interpersonal skills [meaning to be able to work well with people] are required when identifying the stakeholders and this process is not only done in the initial stages of the project but it's an ongoing process that place during the life cycle of the project. This is in line with Alladi and Vadari (2011) who opined different stakeholders are involved at different phases of a project. In this regard people skills are crucial in stakeholder identification. The project team should be able to make deliberate attempts to exert influence on project stakeholders and this requires skills to be able to work well with people. They must then determine the expectations and interests desired by each stakeholder and this can be achieved if the team has good relations with the stakeholders.

\section{Conclusion and recommendations}

This research took the approach that identification of stakeholders is an ongoing process and there are different stakeholders in different life cycle of the project. Nevertheless, stakeholder identification is one of the changing aspects in project therefore it demands a highly preforming team with skills that are complementary. Stakeholder identification begins with the internal stakeholders and these are the project team. To identify the team members requires relationship building and communication skills. Even though identification of external stakeholders requires more of intellectual, people and conceptual skills, the communication and relationship building are also essential in these stakeholders. However, for the team to be able to perform well the project leader should be able to motivate and empower the project team to reach their full potential and by doing that he /she has to remove obstacles, share a vision and trust that the team members will be responsible and succeed since they have complementary skills. The team leader has to have high level of trust and give the team members space to exercise their skills as they complement each other.

An interesting thing to note is that the skills discussed above build on each other and if it is done properly, they will strengthen each other. Good communications skills are central first between the project team members, between the project team and the external stakeholders and between the external stakeholders themselves. People skills and relationship building are built on good communication skills. Without the good communication between the stakeholders and the team relationships will be difficult to build.

With existing managerial skills (conceptual, technical and human), identified essential skills i.e relationship building \& communication skills for internal stakeholder; intellectual, conceptual, communication and people skills for external stakeholders are found for identifying project stakeholders considering sustainability issues that is to some extent separated from traditional project management skills.

Only one database Summons (Malmo University Database) and some selective journals were used for creating data that was one of the major limitations of this study. Besides that only 10 relevant articles were considered for collecting data. Still there are lot of opportunity to explore more regarding on this issues reviewing big database and high number of articles.

We therefore recommend shared leadership in project as it allows the team to be more motivated and independent without having to be told what to do and how to do it. However a team leader comes hand in the sense that he has to identify appropriate people who will be able to work together in harmony. Future research, given the fact that there are a lot of strategies and tools for identifying stakeholders, it will be of use to have empirical research on which skills are needed for each strategy, as this will help the team leaders to select appropriate team members and also other external stakeholders.

\section{References}

6, P. \& Bellamy, C. (2012). Principles of Methodology - Research Design in Social Science. Thousand Oaks: Sage Publication.

Alladi, A. \& Vadari, S. (2011). Systemic approach to project management: A stakeholder's perspective for sustainability. Paper presented at the pp. 1-4. doi:10.1109/INDCON.2011.6139635

Ballejos, L. C. \& Montagna, J. M. (2008). Method for stakeholder identification in inter-organizational environments. Requirements Engineering, 13(4), 281-297. Doi: 10.1007/s00766-008-0069-1 
Blaikie, N. (2003). Analyzing Quantitative Data - From Description to Explanation. Thousand Oaks: Sage Publication.

Bourne, L. \& Walker, D. H. T. (2005). Visualizing and mapping stakeholder influence. Management Decision, 43(5), 649-660. Doi: 10.1108/00251740510597680

Clarkson, M. (1995). A stakeholder framework for analyzing and evaluating corporate social performance. Academy of Management Review, 20(1), 92-117.

Cobb, A. T. (2012). Leading Project Teams. (2nd Ed.). Los Angeles: Sage Publications

Davies, A., Gann, D. \& Douglas, T. (2009). Innovation in megaprojects: systems integration at London Heathrow Terminal 5. California Management Review, 51 (2), pp.101- 125.

Donaldson, T. \& Preston, L. E. (1995). The stakeholder theory of the corporation: Concepts, evidence, and implications. The Academy of Management Review, 20(1), 65-91.

Donaldson, T. and Preston, L. (1995). The stakeholder theory of the corporation: Concepts, evidence, and implications. Academy of Management Review, 20(1), 65-91.

Dulewicz, V. \& Higgs, M. (2003). Design of a new instrument to assess leadership dimensions \& styles. In: Henley Working Paper HWP 0311. Henley Management College, Henley-on-Thames, UK.

Eskerod, P. \& Huemann, M. (2013). Sustainable development and project stakeholder management: What standards say? International Journal of Managing Projects in Business, 6(1), 36 - 50.

Eskerod, P. \& Vaagaasar, A. L. (2014). Stakeholder Management Strategies and Practices during a Project Course. Project Management Journal, 45 (5), 71-85

Freeman, R. E. (1984). Strategic management: A stakeholder approach. Boston: Pitman Publishing.

Frye, C. M., Bennett, R. \& Caldwell, S. (2006). Team emotional intelligence and team interpersonal process effectiveness. American Journal of Business 21 (1), 49-58

Galvin, T., Gibbs, M., Sullivan, J., \& Williams, C. (2014). Leadership Competencies of Project Managers: An Empirical Study of Emotional, Intellectual, and Managerial Dimensions. Journal of Economic Development, Management, IT, Finance and Marketing, 6(1), 35-60, 35

Jepsen, A. L. \& Eskerod, P. (2009). Stakeholder analysis in projects: Challenges in using current guidelines in the real world. International journal of project management 27(4), 335-343

Jergeas, G. F., Williamson, E., Skulmoski G. J. and Thomas, J. (2000). Stakeholder Management on Construction Projects. AACE International Transaction, P12.1-P12.6.

Karlsen, J. T. (2002). Project stakeholder management. Engineering Management Journal 14(4): 19-24.

Landin, A. (2000). Impact of Quality Management in the Swedish Management, 1:2(1983), pp 83-87 Management, Lund University.

Northouse, P. (2013). Leadership - Theory and practice. (6th ed). Thousand Oaks: Sage publications.

Olander, S. \& Lundin A. (2005). Evaluation of stakeholder influence in the implementation of construction. International journal of project management, 23, 321-328

Olander, S. (2007). Stakeholder impact analysis in construction project management. Construction management and economics, 25 (3), 277-287

Pfeffer J. and Salancik G. R. (1978). The External Control of Organizations. Harper \& Row Publications, New York.

Prabhakar, G. P. (2008). What is project success: A literature review? International Journal of Business and Management, 3 (9). pp. 3-10. ISSN 1833-3850

Project Management Institute (2008). A guide to the project management body of knowledge (PMBOK® guide). 4th ed. Newton Square (PA): Author.

Roloff, J. (2008). Learning from Multi-Stakeholder Networks: Issue-Focused Stakeholder Management. Journal of Business Ethics, 82 (1), pp. 233-250, DOI: 10.1007/s10551-007-9573-3.

Savage, G. T., Nix, T. W., Whithead, C. J., \& Blair, J. D. (1991). Strategies for assessing and managing organizational stakeholders. Academy of Management Executives, 5(2), 61-75.

Schieg, M. (2009). The model of corporate social responsibility in project management. Business: Theory \& Practice, 10(4), 315-321.

Silverman, D. (2011). Qualitative Research. (3rd ed). Thousand Oaks: Sage Publishers.

Tolbert, P. S., \& Hall, R. H. (2009). Organizations: Structures, Processes and Outcomes $\left(10^{\text {th }} \mathrm{ed}\right)$. Upper Saddle River: International Pearson Education.

Turner, J. R. \& Müller, R. (2005). The project manager's leadership style as a success factor on projects: a literature review. Project management journal, 36 (1). pp. 49-61. 
Walker, D. H. T., Bourne, M. L. and Shelley, A. (2008). Influence, stakeholder mapping and visualization. Construction Management and Economics 26(6): 645-658.

Werther W. B. Jr., \& Chandler, D. (2011). Strategic Corporate Social Responsibility - Stakeholders in a Global Environment. (2nd ed). Thousand Oaks: Sage publications.

Yueh-shian, L. (2011). Creating and Managing Global Organizational Teams. Journal of Global Business Issues. High Beam Research 5(1) 73-77. 